\title{
PROGRAMAS TELEVISIVOS E SUAS ESTRUTURAS NARRATIVAS: ENREDO, PERSONAGENS, TEMPO, ESPAÇO E FOCO NARRATIVO EM TELEDRAMATURGIA E ENTRETENIMENTO
}

\author{
TELEVISION PROGRAMS AND THEIR NARRATIVE STRUCTURES: \\ ENREDO, CHARACTERS, TIME, SPACE AND NARRATIVE FOCUS ON \\ TELEDRAMATURGY AND ENTERTAINMENT
}

João Paulo Hergesel ${ }^{1}$

\section{RESUMO}

Este texto, cuja dimensão discursiva transita entre o ensaio acadêmico e o manual teórico, reflete sobre um procedimento metodológico interdisciplinar que deriva da Literatura, mas que pode ser aplicado em análises de produtos audiovisuais, sobretudo de obras televisivas. O objetivo é revisitar as noções de enredo, personagens, tempo, espaço e foco narrativo tão caras ao estruturalismo - e propor sua observação em programas de televisão, principalmente em teledramaturgia e entretenimento. A metodologia engloba um estudo bibliográfico e interpretativo de categorias da Narratologia, disciplina que orbita entre as Letras e a Comunicação. Os resultados apontam que as ideias que estiveram em voga nos anos 1970 ainda são úteis para compreensão de fenômenos da cultura de massa, em suas narrativas contemporâneas.

Palavras-chave: Interdisciplinaridade. Comunicação. Literatura. Televisão. Narrativas.

\section{ABSTRACT}

This text, whose discursive dimension transits between the academic essay and the theoretical manual, reflects on an interdisciplinary methodological procedure that derives from Literature, but which can be applied in analyses of audiovisual products, especially television works. The aim is to revisit the notions of plot, characters, time, space and narrative focus - so dear to structuralism - and propose their observation in television programs, especially in theater and entertainment. The methodology encompasses a bibliographic and interpretative study of categories of Narratology, a discipline that orbits between Letters and Communication. The results point out that the ideas that were in vogue in the 1970s are still useful for understanding phenomena of mass culture in their contemporary narratives.

Keywords: Interdisciplinarity. Communication. Literature. Television. Narratives.

Data de submissão: 22 jun. 2019.

Data de aprovação: 14 maio 2020.

\footnotetext{
${ }^{1}$ Doutor em Comunicação pela Universidade Anhembi Morumbi (UAM). Professor do Programa de PósGraduação em Linguagens, Mídia e Arte da Pontifícia Universidade Católica de Campinas (PUC-Campinas). Lattes: http://lattes.cnpq.br/0081045915422658. Orcid: http://orcid.org/0000-0002-1145-0467. E-mail: joao.hergesel@puc-campinas.edu.br.
} 


\section{INTRODUÇÃO}

Este texto é um recorte da tese de doutorado A televisão brasileira em ritmo de festa: a telepoética nas produções do SBT (HERGESEL, 2019), orientada pelo Prof. Dr. Rogério Ferraraz e defendida em 12 de abril de 2019 no Programa de Pós Graduação em Comunicação da Universidade Anhembi Morumbi - UAM. Trata-se, ainda, de uma versão revista e ampliada das ideias expostas em oficina ministrada no 41 을 Congresso Brasileiro de Ciências da Comunicação (HERGESEL, 2018), evento realizado na Universidade da Região de Joinville - Univille, de 2 a 8 de setembro de 2018. Dialoga, ainda, com o projeto de pesquisa Arte e inovação na televisão brasileira: discursos, poéticas e tecnologias da TV Cultura, em desenvolvimento no Programa de Pós-Graduação em Linguagens, Mídia e Arte (PPG-LIMIAR) da Pontifícia Universidade Católica de Campinas (PUC-Campinas) desde 01/02/2020.

Ao longo deste trabalho, cuja dimensão discursiva transita entre o ensaio acadêmico e o manual teórico, buscou-se refletir sobre um procedimento metodológico interdisciplinar que deriva da Literatura, mas que pode ser aplicado em análises de produtos audiovisuais, sobretudo de obras televisivas. O objetivo é revisitar as noções de enredo, personagens, tempo, espaço e foco narrativo - tão caros ao estruturalismo - e propor sua observação em programas de televisão, especialmente em teledramaturgia e entretenimento. A metodologia adotada engloba um estudo bibliográfico e interpretativo de categorias da Narratologia, disciplina que orbita entre as Letras e a Comunicação.

Resgatando o histórico registrado em estudos antecedentes (HERGESEL; SILVA, 2018), conceitua-se a Narratologia - termo cunhado por Tzvetan Todorov (1973), em seu $A$ gramática do Decameron, lançado originalmente em 1969 - como o campo de estudos das narrativas. Narrativa, tal como citada por Aristóteles, em sua Retórica, é uma produção cultural caracterizada por enunciar a apresentação de um caso, prosseguido por um conflito, acarretando no discorrimento de ações, direcionando-se a um ponto culminante que se desprende na resolução desse emaranhado.

Em discussão mais recente e direcionada ao audiovisual, David Bordwell (2005, p. 278) recupera as noções de syuzhet e fabula, utilizadas pelo formalismo russo, sendo syuzhet (ou trama) o modo como a narrativa é apresentada e fabula (ou história) a ordem 
cronológica dos eventos trazidos pela narrativa. Para além dessa divisão, no entanto, vê-se necessário considerar os elementos fundamentais da narrativa primordial - enredo, personagens, tempo, espaço e foco narrativo - que ainda são utilizados nas narrativas contemporâneas.

Também nesse espectro estruturalista de se entender a narrativa, surgiram outras vertentes, distintas, mas complementares, entre as quais se destacam: um conjunto de etapas pelas quais um herói transita para conquistar seus objetivos e retornar ao seu território de origem (a "jornada do herói" ou "monomito", de Joseph Campbell); um conjunto de características coincidentes nos contos de cunho fantástico (a "morfologia do conto maravilhoso", de Vladimir Propp); a criação de mitos e o combustível cultural que eles possuem (o "mito", de Roland Barthes); um modelo de como se comportam as ações de determinados personagens dentro das narrativas (as "funções actanciais", de A. J. Greimas); construções de personalidades-modelo, levando em consideração o que existe em um imaginário coletivo (os "arquétipos", de Carl Gustav Jung).

Independentemente do percurso utilizado para sua composição, narrar tem como significado geral descrever as movimentações de um evento, real ou fictício, envolvido, de alguma forma, em um discurso idiossincrático, que apresenta variações de autor para autor - e consequentemente variadas possibilidades de interpretação para seu consumidor final. Em televisão, a narrativa ganha espaço na dramaturgia (séries, novelas, telefilmes), no jornalismo (reportagens, documentários, narração de fatos) e no entretenimento (histórias de vida, reality shows, diálogos).

A recomendação em utilizar os estudos de Todorov para compreensão de fenômenos narrativos é justificada pelo próprio autor (TODOROV, 2006, p. 70): explorar a estrutura é sinônimo de não se satisfazer com a mera descrição do objeto, nem com uma interpretação fundamentada na psicologia, na sociologia ou na filosofia. Portanto, analisar narrativas televisivas, a partir de sua estrutura, é tentar compreender os motivos que levaram à sua criação, os efeitos potenciais de sua fruição, a representação sociocultural de sua produção e os possíveis reflexos de sua disseminação.

Para discorrer sobre as categorias da narrativa, em seu aspecto estruturalista, e elucubrar sobre como elas podem se manifestar na televisão, elabora-se uma síntese a partir 
da obra coletiva assinada por Roland Barthes, A. J. Greimas, Claude Bremond, Umberto Eco, Jules Griti, Violette Morin, Cristian Metz, Tzvetan Todorov e Gérard Genette (2011). Também se somam ao corpo teórico as leituras de Benjamin Abdala Junior (1995), Candida Vilares Gancho (2002) e Carlos Ceia (2018).

\section{TELE-ENREDO}

A narrativa televisiva, ficcional ou verídica, cria em si uma dimensão chamada diegese, que consiste em uma espécie de mundo narratológico. Elementos que fazem parte desse mundo são considerados diegéticos; elementos que não pertencem a esse mundo são extradiegéticos; e elementos que extrapolam a diegese - criando uma espécie de novo mundo dentro do mundo já criado (como um devaneio ou uma passagem onírica) - são os intradiegéticos.

A diegese abriga em si todo o conteúdo oferecido pela narrativa: desde a introdução (início do que será explanado) até a resolução (conclusão do fenômeno narrado), compreendendo quaisquer obstáculos (ações; descrições e circunstâncias suplementares às ações; e diálogos necessários para o desenvolvimento das ações; dentre outros elementos) que estejam presentes na mensagem propagada.

O percurso que será percorrido na diegese, por sua vez, é o enredo, que se divide em quatro partes: (a) exposição: apresentação breve dos personagens, tempo e espaço; (b) complicação: conflito entre as personagens, causando tensão; (c) clímax: ápice da narrativa, parte com maior impacto; (d) desfecho: conclusão do conflito. O enredo, portanto, pode ser cronológico - quando há a presença de uma sequência (exposição > conflito > clímax > desfecho) - ou psicológico - quando é interior (deixando o presente de lado para retomar o passado ou projetar o futuro).

$\mathrm{Na}$ televisão, os enredos - ou tele-enredos - podem surgir de pelo menos três formas: fechado (como em um telefilme, uma reportagem, uma série gravada antes da exibição), semiaberto (como em uma telenovela, que tende a se modificar conforme a audiência registrada e a devolutiva dos espectadores) ou em processo (como em programas 
de auditório, sobretudo ao vivo, que edificam suas histórias no palco, muitas vezes interrompidos por elementos extradiegéticos ou pertencentes a outras diegeses).

\section{TELEPERSONAGENS}

Para que a narrativa ganhe movimentação e consiga se desenvolver, existem os personagens, isto é, os seres animados que executam as ações e participam da sequência temporal proporcionada pelo enredo. Os personagens - sejam humanos (como nas novelas), sejam animais (como nas fábulas), sejam objetos (como nos apólogos) - são identificados de acordo com sua relevância, com sua composição e com sua caracterização.

Quanto à relevância, existem o protagonista, o antagonista e os deuteragonistas. O protagonista é o personagem principal, caracterizado como o centro da história, de quem as ações giram ao entorno. O antagonista é geralmente portador de uma psique malévola e busca prejudicar ou criar obstáculos, conflitando com o percurso do protagonista. Já os deuteragonistas (ou coadjuvantes), também chamados de personagens secundários, apesar de terem um destaque menor se comparado ao dos outros dois papéis, continuam sendo fundamentais para o desenvolvimento da trama.

Sobre a composição, caracteriza-se o personagem como sendo plano, redondo, tipo ou coletivo. O plano (ou desenhado) é o mais simplório, não evolui durante a narrativa e pode, muitas vezes, ser considerado previsível por apresentar características estáveis e repetitivas. O redondo (ou esférico) é o mais complexo, apresentando traços que se modificam conforme o andamento da narrativa, tornando-o imprevisível. O personagem tipo surge quando o personagem acaba se tornando estereotipado, relacionado a uma função social (o caipira, por exemplo). Já o coletivo corresponde a um grupo de indivíduos que atua de maneira animada, depreendendo uma vontade em comum, como se fosse um único ser (a família, por exemplo).

A respeito da caracterização, em cada personagem se torna perceptível uma concepção sobre seu perfil psicológico e social, não se restringindo à aparência e a seu detalhamento físico. A caracterização física está associada aos traços corporais; a psicológica apresenta relação com a maneira de ser juntamente dos valores éticos e morais; a social 
compreende a profissão que dado personagem exerce na narrativa, bem como seu relacionamento com os demais, também inseridos em um contexto político.

Em televisão, os personagens - ou telepersonagens - são mais facilmente visíveis em histórias de ficção (a vítima e o vilão; o bobo e o justiceiro; etc.), mas podem estar encapados pelas funções de repórter, apresentador ou, ainda, participante da plateia. Explica-se: ao passo que o telejornalismo e o entretenimento produzem narrativas, assim como a dramaturgia, é sensato que se atribua a função de personagem aos seres que coabitam as diegeses processadas por diferentes formatos.

\section{TELETEMPO}

As narrativas - que são guiadas por um enredo e movimentadas por personagens dispõem de alguns níveis de temporalidade, que podem ser considerados internos ou externos. Os tempos internos dizem respeito à diegese em si e a maneira como ela se desenrola: se cronologicamente ou psicologicamente. Já os tempos externos mostram mais relação com quem produz, o momento em que produz e quem consome.

O tempo cronológico é o tempo do desenrolar da ação, em que os fatos são narrados na ordem em que acontecem (do prólogo ao epílogo, geralmente sem desvios). Conforme o caso, a unidade de tempo é indicada - horário ou data - ou representada por uma comemoração marcante (Páscoa ou Natal, por exemplo). Mesmo que não sejam evidentes a todo momento, também são comuns expressões como "no dia seguinte" ou "algum tempo depois".

Diferentemente do tempo cronológico, o tempo psicológico não é mensurável. Dessa maneira, flui na mente das personagens. Não há uma linha cronológica precisa, havendo quebras na ordem da apresentação dos fatos. Em alguns momentos, antecipa-se um acontecimento; em outras passagens, recua-se no tempo e volta-se ao passado, sem prévio aviso. A narrativa com esse tempo apresenta um fluxo internamente ligado ao personagem e aos seus conflitos, reflexões e emoções.

Externo à narrativa, o tempo do escritor (ou tempo da enunciação) aborda a própria vida do autor, ou seja, sua idade biológica bem como as experiências já vividas. Isso enuncia, 
por exemplo, que o estilo de um autor é variável: uma obra lançada no início de carreira é, possivelmente, menos madura e polida do que uma produzida após alguns anos de prática. Em contexto televisivo, esse conceito acaba se expandindo para a equipe de produção num geral: as características da produtora, a experiência de mercado, o público que atinge etc.

O tempo do leitor (ou tempo da percepção) é o modo como o espectador interpreta a obra: uma mesma narrativa pode ser entendida de uma maneira no início da adolescência e de maneira diversa quando esse leitor estiver na fase adulta, por exemplo. Por último, o tempo histórico é a época em que a narrativa foi criada e o contexto sócio-político-cultural que embasa essa atmosfera.

Em televisão, o tempo - ou teletempo - geralmente é bem estipulado, mas está à mercê das surpresas provocadas pela programação. Para ilustrar esse raciocínio, tem-se em mente a reprise de uma telenovela: dificilmente um episódio que se passou no Natal na época de sua exibição original (e por isso traz elementos natalinos para o audiovisual) coincidirá com essa data novamente. Outro exemplo é um programa ao vivo, que pode ter sua narrativa encurtada para acrescentar informações de última hora.

\section{TELE-ESPAÇO}

As narrativas - que são guiadas por um enredo e movimentadas por personagens em uma específica noção de tempo - precisam de um ambiente para serem realizadas. O lugar onde essas ações se passam - que pode ser ilimitado (como o universo) ou restrito (como um dormitório) - é denominado espaço. Quer decorativo (quando apenas enfeita a história), quer funcional (quando auxilia na narração), o espaço pode ser físico (ambiente pelo qual circulam as personagens) ou abstrato (englobando o espaço social e o psicológico).

O espaço físico assimila os aspectos geográficos, os pontos de referência, os objetos de decoração, entre diversos elementos que facilitam a construção do cenário da obra, tanto interno como externo. Já o espaço social aglomera o contexto sócio-econômico-cultural do local em que a diegese se apresenta, registrando, assim, os hábitos e valores da sociedade onde dado personagem está introduzido. 
O espaço psicológico, por sua vez, é um cenário criado pela mente do próprio personagem e que transmite ao leitor a possibilidade de conhecer as expectativas e emoções internas do personagem em uma visão mais intimista. Trata-se de um local em que os personagens se encontram consigo próprios, na sua essência, criando uma atmosfera interior que dá vida a pensamentos, reflexões, divagações, sentimentos e emoções. Uma vez que este pode não fazer parte do espaço físico e social, tem sua representação dada por meio de monólogos.

Em televisão, o espaço - ou tele-espaço - ganha mais atenção do que na literatura, por exemplo, visto que os recursos visuais são mais acentuados e chegam ao espectador de forma mais rápida e sem muito esforço. Assim como no cinema, os espaços televisuais são representados por cidades cenográficas, estúdios ou até mesmo efeitos digitais, em prol da verossimilhança.

\section{TELENARRADOR}

As narrativas - que são guiadas por um enredo e movimentadas por personagens em uma específica noção de tempo dentro de um espaço - são registradas sob algum ponto de vista, o que determina quais cenas serão exibidas e quais serão omitidas. O modo de narrar, que está muito mais atrelado à trama do que à história, é o que configura o foco narrativo, que pode ser constituído em primeira pessoa - o narrador participa da história (evidencia-se a presença do "eu") - ou em terceira pessoa - expõe-se a história de outrem, sem participação.

Partindo desse ângulo, o narrador pode assumir aspectos a respeito do tipo e da classificação. Existem dois tipos de narrador em primeira pessoa - narrador personagem (ou narrador protagonista) e narrador personagem secundária - e dois tipos de narrador em terceira pessoa - narrador observador e narrador onisciente.

O narrador personagem (ou narrador protagonista) é o centro da narrativa e se envolve nos acontecimentos; já o narrador personagem secundária participa dos acontecimentos, mas não é o personagem central, apesar de fazer parte do círculo de amizades. Paralelamente a isso, o narrador observador relata os acontecimentos criados ou 
vividos pelos personagens, como o que aconteceu, o que as personagens disseram e, principalmente, suas ações e suas atividades; o narrador onisciente, além de retratar as ações dos personagens, também revela o que elas sentem e pensam.

No que tange à classificação do narrador, este pode ser enxergado em três óticas: heterodiegética, autodiegética e homodiegética. O narrador heterodiegético (= diegese do outro) não participa da narrativa; o narrador autodiegético (= diegese de si) é o que, além de participar da narrativa, ainda é protagonista; o narrador homodiegético (= diegese do semelhante), por fim, é aquele que participa da narrativa, mas não assume a posição de protagonista.

Em televisão, o narrador - ou telenarrador - dificilmente será autodiegético ou homodiegético, tendo em vista a demanda necessária para que se registre toda a produção em câmera subjetiva (somente assim o narrador assumiria, também, a posição de personagem). Contudo, mesmo na narração heterodiegética, nota-se um predomínio do narrador observador, o que pode resultar em uma fidelidade da audiência - que, por não estar ciente de todos os detalhes da narrativa, fica apreensiva para os desdobramentos.

\section{PROGRAMAS DE AUDITÓRIO COMO CONTENTORES DE} NARRATIVA

De acordo com Vera França (2006, p. 10), "programas televisivos são narrativas que refletem e constroem imagens, representações e valores sociais. Constituem também interlocuções complexas, em que estão enredados diferentes atores sociais". Por "programas televisivos" não podemos nos prender à referência à teledramaturgia, mas também ao jornalismo e ao entretenimento. Ao passo que reportagens e documentários produzem uma narrativa do cotidiano, registrando pelo audiovisual a realidade do contemporâneo, os reality shows e programas de auditório confeccionam narrativas em processo.

Para explanar esse raciocínio, é preciso relembrar que entendemos como narrativa toda obra guiada por um enredo e movimentada por personagens em uma específica noção de tempo dentro de um espaço, sob um determinado foco narrativo. Essa definição, como 
poderá ser observado ao longo deste trabalho, não se limita à ficção seriada, mas a outras tantas formas de apresentar fatos e ideias.

Inicialmente, temos de considerar que, em se tratando de televisão, a narrativa seriada não é o único modo de manifestação de uma narrativa ficcional. As telenovelas, as séries televisivas e suas ramificações - seriado, minissérie, microssérie, macrossérie, supersérie etc. (cujos aspectos discursivos e distinções entre si não são foco desta pesquisa) - compõem o núcleo de teledramaturgia ao lado de teleteatros, telefilmes, esquetes televisivos, teasers, entre outras denominações de obra única.

Também é necessário ter em mente que a ficção televisiva não é detentora absoluta das narrativas, já que a não ficção pode compor fenômenos comunicacionais desse tipo. Seja de modo seriado, seja unitário, o telejornalismo, por exemplo, produz obras que, muitas vezes, encaixam-se no perfil de narrativas, uma vez que não se limitam a transmitir informações ou a ler notícias, mas a explorar o potencial comunicativo e cultural de um acontecimento - como em séries documentais ou documentários televisivos.

Por fim, é ainda fundamental esclarecer que, dentro da não ficção, as narrativas não são exclusividade dos programas jornalísticos. Histórias são formadas dentro de outros formatos televisivos, como os game shows, as entrevistas, os reality shows, os concursos de talento, entre demais variedades - independente do fato de os elementos narrativos estarem explícitos e/ou serem facilmente identificáveis. Luiz Carlos Travaglia (2007) cita o que seria uma narrativa de não história, diferenciando-a da tradicional narrativa de história:

No caso da espécie história da narração, os episódios aparecem encadeados entre si, caminhando para um desfecho ou resolução e um resultado. Já na espécie não história da narração, os episódios estão lado a lado no texto, mas não se encadeiam, conduzindo a uma resolução e a um resultado (TRAVAGLIA, 2007, p. 43).

Muito embora a observação de Travaglia esteja mais direcionada ao texto escrito do que à modalidade de expressão audiovisual, é notável sua transição para a televisão: programas de variedades, em geral, parecem não seguir uma lógica narrativa, mas suas atrações caminham paralelamente para a construção de um todo, o organismo que dará sentido ao programa em si. Em estudos prévios, constatou-se que "é possível afirmar, 
portanto, que os programas de auditório são macronarrativas em que habitam várias diegeses, cada qual com seus enredos e personagens específicos" (HERGESEL; FERRARAZ, 2018, p. 12).

Para Carmen Ligia Cesar Lopes Torres (2004, p. 64), “a linguagem coloquial e direta dos programas de auditório pressupõe uma narrativa com as mesmas características", isto é, "objetiva, com baixo nível de ambiguidade, pouca utilização de metáforas e, na maior parte das vezes, referenciada em fatos da vida real". Ainda nessa relação entre programas de auditório e as narrativas que eles apresentam, a autora expõe:

O gênero programas de auditório é definido como uma mistura de formatos televisivos, nos quais acontecem narrativas ficcionais, narrativas sobre fatos reais, como as notícias, experiências artísticas - música e dança -, além de debates de ideias sobre assuntos diversos e descrições e narrativas de histórias da vida real, estas últimas como ponto de partida para ações assistenciais (TORRES, 2004, p. 171-172).

De acordo com Ignácio Coqueiro² ${ }^{2}$ diretor de televisão, existe uma proximidade entre a dramaturgia e o entretenimento, coincidindo elementos da telenovela nos programas de auditório. Em entrevista para Renan Feitosa de Oliveira e Dirceu Lemos da Silva (2016), esclarece:

O público brasileiro se acostumou com novela; então, a dramaturgia está inserida de certa forma em todos os lugares, não só na novela, não só na minissérie; ela está integrada em uma necessidade que o público tem de acompanhar uma história [...]. Então, o programa de auditório, por mais que venha um cantor, ele vem acompanhado de uma história. Fazer um programa de auditório feito uma salada de fruta não dá certo, ele tem que ser pensado e conduzido para aquilo. Tem que ter uma narrativa, para o público poder pegar (aí você pode ter uma narrativa mais sofisticada, menos sofisticada (OLIVEIRA; SILVA, 2016, p. 10).

Nesse misto de narrativas (ficcionais, factuais e biográficas), forma-se o programa de auditório enquanto gênero televisivo. Prosseguindo com esse raciocínio, Oliveira e Silva aprofundam o caso das histórias de vida, muito presentes nos programas de auditório, e

\footnotetext{
${ }^{2}$ Ignácio Coqueiro (Rio de Janeiro, 6 de setembro de 1957) é um diretor de televisão e cinema, responsável por produções como as telenovelas Mulheres de Areia (Rede Globo, 1993) e Máscaras (RecordTV, 2015) e os programas de auditório Caldeirão do Huck (Rede Globo, 2000-2005) e Xuxa Meneghel (2016-2017).
} 
reforçam que "as narrativas de pessoas anônimas são o apoio para as matérias externas. É uma relação de ambivalência, onde dois interesses são atendidos, a história do anônimo que se deixa expor e o interesse da audiência" (OLIVEIRA; SILVA, 2016, p. 12).

Se existe tal aproximação entre os programas de auditório e a ficção seriada, podemos inferir que as estruturas narrativas dos programas de entretenimento são similares às da teledramaturgia, permitindo uma abordagem acerca de elementos como enredo, personagens, tempo, espaço e foco narrativo. A depender de como a produção é guiada (a poética televisiva), torna-se possível identificar como cada uma das categorias narrativas se manifestam, de maior ou de menor modo ${ }^{3}$.

Os programas de auditório, portanto, parecem seguir a noção de uma narrativa sideral: existem diversas micronarrativas sendo eclodidas e/ou desenvolvidas e/ou encaixadas - ora independentes, ora entrelaçadas - ao longo de toda exibição, tais como corpos celestes orbitando (às vezes, sem itinerário) em um grande sistema astronômico; quando aproximadas em justaposição ou unificadas por aglutinação, esses astros audiovisuais compõem uma galáxia narrativa, a qual chamamos de macronarrativa.

\section{CONSIDERAÇÕES FINAIS}

É notório que as narrativas televisivas - que são guiadas por um enredo e movimentadas por personagens em uma específica noção de tempo dentro de um espaço, sob um determinado foco narrativo - ganham diferentes perspectivas quando são produzidas e apreciadas. Do processo de criação ao de recepção, passando pela produção e fruição e considerando a devolutiva do público, a ótica narrativa é variável e depende de fatores externos à obra. Por isso, resulta-se inviável buscar uma verdade a respeito dos processos interpretativos das narrativas; entender sua estrutura e seu mecanismo torna-se, aparentemente, mais relevante.

Dessa maneira, os estudos de Roland Barthes, A. J. Greimas, Claude Bremond, Umberto Eco, Jules Griti, Violette Morin, Cristian Metz, Tzvetan Todorov e Gérard Genette

\footnotetext{
${ }^{3}$ Para uma análise mais aprofundada desses programas como narrativas midiáticas, sugere-se a leitura de Estilo SBT de comunicar: análise de programas de auditório (HERGESEL; FERRARAZ, 2018), no qual são estudados os programas Eliana, Domingo Legal e Máquina da Fama.
} 
(2011) - inicialmente aplicados aos estudos literários - continuam se mostrando indicados para que se possa analisar uma narrativa, independente da modalidade linguística (verbal, visual, audiovisual) ou nível de complexidade que apresente. De acordo com a retomada desses estudos e das inflexões registradas neste trabalho, torna-se possível observar, nos programas de televisão, sobretudo de teledramaturgia e entretenimento, as noções de enredo, personagens, tempo, espaço e foco narrativo, tão caras ao estruturalismo.

Conforme mencionado em pesquisas prévias (HERGESEL; SILVA, 2018), enquanto algumas propostas metodológicas buscam apenas tangenciar a obra por meio de paráfrases, baseando-se em subjetivismo e devaneio, o estruturalismo elenca a obra como um todo, levando em consideração atividades internas e externas, funcionando, inclusive, em produtos audiovisuais cotidianos.

\section{REFERÊNCIAS}

ABDALA JUNIOR, Benjamin. Introdução à análise narrativa. São Paulo: Ática, 1995.

BARTHES, Roland; GREIMAS, A. J.; BREMOND, Claude; ECO, Umberto; GRITTI, Jules; MORIN, Violette; METZ, Christian; TODOROV, Tzvetan; GENETTE, Gérard. Análise estrutural da narrativa. Trad. Maria Zélia Barbosa Pinto. 7. ed. Petrópolis, RJ: Vozes, 2011.

BORDWELL, David. O cinema clássico hollywoodiano: normas e princípios narrativos. In: RAMOS, Fernão Pessoa (org.). Teoria contemporânea do cinema. São Paulo: Senac, 2005, v. 2, p. 277-301.

CEIA, Carlos. Arquivo de Encyclopedia. E-dicionário de termos literários, 2018. Disponível em: https://bit.ly/2Jh10Us. Acesso em: 28 fev. 2019.

FRANÇA, Vera. Narrativas televisivas: programas populares na TV. Belo Horizonte: Autêntica, 2006.

GANCHO, Candida Vilares. Como analisar narrativas. São Paulo: Ática, 2002.

HERGESEL, João Paulo. A televisão brasileira em ritmo de festa: a telepoética nas produções do SBT. 2019. Tese (Doutorado em Comunicação) - Universidade Anhembi Morumbi, São Paulo, 2019.

HERGESEL, João Paulo. As narrativas midiáticas infantojuvenis e a televisão: analisando séries e novelas. In: CONGRESSO BRASILEIRO DE CIÊNCIAS DA COMUNICAÇÃO. 41., 2018, 
Joinville, SC. Oficina [...]. Intercom: Joinville, SC, 2018. Disponível em:

https://goo.gl/WMBtxJ. Acesso em: 22 nov. 2018. 70 slides.

HERGESEL, João Paulo; FERRARAZ, Rogério. Estilo SBT de comunicar: análise de programas de auditório. Alumínio, SP: Jogo de Palavras; Votorantim, SP: Provocare, 2018. (Coleção Comunicação, Cultura e Televisão).

HERGESEL; João Paulo. SILVA, Míriam Cristina Carlos. Mídia, narrativa e estilo: literatura, cinema, videoclipe e telejornal. Alumínio, SP: Jogo de Palavras; Votorantim, SP: Provocare, 2018. (Coleção Comunicação, Cultura e Mídia).

OLIVEIRA, Renan Feitosa de; SILVA, Dirceu Lemos da. Do gênero programa de auditório na televisão. In: CONGRESSO BRASILEIRO DE CIÊNCIAS DA COMUNICAÇÃO, 39., 2016, São Paulo. Anais [...]. São Paulo: Intercom, 2016. Disponível em: https://goo.gl/CLkKAw. Acesso em: 08 fev. 2019.

TODOROV, Tzvetan. Gramática del decameron. Madri, Espanha: Taller de Ediciones Josefina Betancor, 1973.

TODOROV, Tzvetan. As estruturas narrativas. Trad. Leyla Perrone-Moisés. 4. ed. São Paulo: Perspectiva, 2006.

TORRES, Carmen Ligia Cesar Lopes. O que o povo vê na TV: programas de auditório e universo popular. 2004. Dissertação (Mestrado em Ciências da Comunicação) - Universidade de São Paulo, São Paulo, 2004.

TRAVAGLIA, Luiz Carlos. A caracterização de categorias de texto: tipos, gêneros e espécies. Alfa, São Paulo, v. 51, n. 1, p. 39-79, 2007. Disponível em: https://goo.gl/grc6Yz. Acesso em: 08 fev. 2019. 